\title{
Lack of Cost-Effectiveness of Preoperative Erythropoiesis-Stimulating Agents and/or Iron Therapy in Anaemic, Elective Surgery Patients: A Systematic Review and Updated Analysis
}

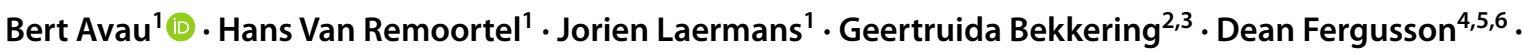 \\ Jørgen Georgsen ${ }^{7}$ Paola Maria Manzini ${ }^{8} \cdot$ Yves Ozier $^{9} \cdot$ Emmy De Buck $^{1,10} \cdot$ Veerle Compernolle ${ }^{11,12}$. \\ Philippe Vandekerckhove ${ }^{10,13}$
}

Accepted: 18 May 2021 / Published online: 8 July 2021

(c) The Author(s) 2021

\begin{abstract}
Objectives For anaemic elective surgery patients, current clinical practice guidelines weakly recommend the routine use of iron, but not erythrocyte-stimulating agents (ESAs), except for short-acting ESAs in major orthopaedic surgery. This recommendation is, however, not based on any cost-effectiveness studies. The aim of this research was to (1) systematically review the literature regarding cost effectiveness of preoperative iron and/or ESAs in anaemic, elective surgery patients and (2) update existing economic evaluations (EEs) with recent data.

Methods Eight databases and registries were searched for EEs and randomized controlled trials (RCTs) reporting cost-effectiveness data on November 11, 2020. Data were extracted, narratively synthesized and critically appraised using the Philips reporting checklist. Pre-existing full EEs were updated with effectiveness data from a recent systematic review and current cost data. Incremental cost-effectiveness ratios were expressed as cost per (quality-adjusted) life-year [(QA)LY] gained.

Results Only five studies (4 EEs and 1 RCT) were included, one on intravenous iron and four on ESAs + oral iron. The EE on intravenous iron only had an in-hospital time horizon. Therefore, cost effectiveness of preoperative iron remains uncertain. The three EEs on ESAs had a lifetime time horizon, but reported cost per (QA)LY gained of 20-65 million (GBP or CAD). Updating these analyses with current data confirmed ESAs to have a cost per (QA)LY gained of 3.5-120 million (GBP or CAD).

Conclusions Cost effectiveness of preoperative iron is unproven, whereas routine preoperative ESA therapy cannot be considered cost effective in elective surgery, based on the limited available data. Future guidelines should reflect these findings.
\end{abstract}

Bert Avau

bert.avau@cebap.org

1 Centre for Evidence-Based Practice (CEBaP), Belgian Red Cross, Motstraat 42, 2800 Mechelen, Belgium

2 Center for Evidence-Based Medicine, Leuven, Belgium

3 Cochrane Belgium, Leuven, Belgium

4 Clinical Epidemiology Program, Ottawa Hospital Research Institute, Ottawa, Canada

5 Department of Medicine, University of Ottawa, Ottawa, Canada

6 Canadian Blood Services, Ottawa, Canada
7 South Danish Transfusion Service, Odense University Hospital, Odense, Denmark

8 SC Banca del Sangue Servizio di Immunoematologia, University Hospital Città della Salute e della Scienza di Torino, Torino, Italy

9 University Hospital of Brest, Brest, France

10 Department of Public Health and Primary Care, Faculty of Medicine, KU Leuven, Leuven, Belgium

11 Blood Services, Belgian Red Cross, Mechelen, Belgium

12 Faculty of Medicine and Health Sciences, Ghent University, Ghent, Belgium

13 Belgian Red Cross, Mechelen, Belgium 


\section{Key Points for Decision Makers}

Routine preoperative erythrocyte-stimulating agents and oral iron treatment for anaemia correction in elective surgery is likely not a cost-effective procedure, with incremental cost-effectiveness ratios of 20-65 million per (quality-adjusted) life-year gained (GBP or CAD), while the evidence on intravenous or oral iron monotherapy is too scarce to make strong conclusions.

Based on the limited data available, erythrocyte-stimulating agents combined with iron are likely not an affordable alternative to blood transfusions in anaemic elective surgery patients. The evidence on cost effectiveness of iron monotherapy, whether intravenous or oral, in these patients is scarce, and given the lack of demonstrated effectiveness, routine use may not be warranted until further evidence on effectiveness emerges.

\section{Introduction}

Elective surgery occasionally causes significant blood loss $[1,2]$. Blood transfusions save lives, but exceptionally are associated with adverse events (e.g. Hepatitis $\mathrm{C}$ virus infection: 0.87 per million transfused blood components; transfusion-related acute lung injury: 8.1 per 100,000 transfused blood components) [3, 4]. 'Patient Blood Management' (PBM) is an evidence-based, multidisciplinary approach to optimizing the care of patients who might need transfusion [5]. PBM encompasses all aspects of patient evaluation and clinical management surrounding the transfusion decisionmaking process, including the application of appropriate indications, as well as minimization of blood loss and optimization of patient red cell mass. PBM thus aims for best practice in transfusion medicine and consists of three cornerstones: (1) addressing pre-existing preoperative anaemia, (2) minimizing perioperative blood loss, and (3) rational use of blood products [6].

Preoperative anaemia is defined by the World Health Organisation (WHO) as a haemoglobin level $<13 \mathrm{~g} / \mathrm{dL}$ for males and $<12 \mathrm{~g} / \mathrm{dL}$ for females [7]. Several approaches to address preoperative anaemia exist, including iron supplements in case of iron deficiency and/or erythropoiesis-stimulating agents to increase the production of red blood cells [8]. The International Consensus Conference on Patient Blood Management (ICC-PBM) of 2018 resulted in a weak recommendation to (1) use iron to correct preoperative iron deficiency anaemia; (2) not routinely use erythrocyte-stimulating agents (ESAs) in anaemic elective surgery patients, but to consider the use of short-acting ESAs combined with iron in anaemic patients scheduled for major orthopaedic surgery [9]. It was acknowledged that there was insufficient evidence regarding the long-term effects of ESAs. A research recommendation was therefore formulated to investigate the longterm effects of ESAs - undesirable effects, optimal dosage, co-presence of iron deficiency, and cost effectiveness.

The effectiveness and undesirable effects of erythropoietin (EPO) and/or iron therapy have been investigated by our team in separate systematic reviews ([10] and submitted for publication). These concluded that intravenous or oral iron therapy may not reduce the number of patients transfused [10]. Furthermore, ESAs combined with iron therapy probably reduce the number of patients transfused. When it comes to the adverse effects of EPO and/or iron therapy, only very low certainty evidence was identified, which means the risk profile remains uncertain (submitted for publication).

The aim of this systematic review was to identify robust scientific evidence on cost effectiveness of ESAs and/or iron therapy, according to the following PICO question: In anaemic elective surgery patients $(\mathrm{P})$, is using iron monotherapy or ESA+iron therapy (I), compared with not using iron monotherapy or ESA+iron therapy $(\mathrm{C})$, cost effective (O)? In addition, we updated the identified robust cost-effectiveness analyses using the most up-to-date data on costs and effectiveness.

\section{Methods}

This systematic review is planned and reported in accordance with the Preferred Reporting Items for Systematic Reviews and Meta-Analyses (PRISMA checklist, Online Resource 1, see electronic supplementary material [ESM]). See Online Resource 2 for an extended Methods section. No a priori published protocol exists.

\subsection{Systematic Review}

We included economic evaluations and randomized controlled trials (RCTs) reporting an incremental cost effectiveness ratio (ICER), comparing iron as a monotherapy or in combination with ESA, in any dose, duration and formulation to control, in adult elective surgery patients with preoperative anaemia [7].

Search strings, consisting of free-text words and indexing terms, were designed to search for relevant publications in eight databases: Medline, The Cochrane Library, Embase, Transfusion Evidence Library, ISI Web of Science, International Network of Agencies for Health Technology 
Assessment/Centre for Reviews and Dissemination HTA database, ClinicalTrials.gov, and WHO International Clinical Trials Registry Platform. The search was performed on November 11, 2020, without restrictions regarding publication dates or language (Online Resource 3, see ESM). Additionally, reference lists and the twenty first 'related citations' in Medline were screened for additional relevant studies. Study authors were contacted to obtain additional publications.

Studies were assessed by two reviewers independently (BA and HVR) at title/abstract and full-text level, in EppiReviewer 4.0 [11]. Findings were synthesized narratively and meta-analyses were not planned given the anticipated heterogeneity in included models' input variables and assumptions. Data were extracted and reporting quality was assessed in duplicate (BA and HVR) using the Philips reporting checklist for economic evaluations [12]. This checklist consists of three main domains: structure, data and consistency. Each of these domains contains several signalling questions, resulting in a total of 56 reporting items to assess.

Discrepancies between reviewers regarding study selection, data extraction and quality appraisal were resolved by discussion. Where necessary, a third reviewer could be consulted (JL).

\subsection{Additional Sensitivity Analyses}

Identified economic evaluations with a lifetime time horizon on the cost effectiveness of EPO and iron [13, 14] were updated with recent cost and effectiveness data. Updated clinical effectiveness data, proportion of patients transfused and number of allogeneic blood units transfused, were based on a systematic review that was a part of the same project as the current review [10]. Current cost data regarding EPO, iron and allogeneic blood products were based on market prices obtained through multi-country surveys (Online Resource 4, see ESM). Separate sensitivity analyses were made with the highest reported costs for EPO and iron and lowest reported cost for allogeneic blood products (least conservative scenario) and with the lowest reported costs for EPO and iron and the highest reported cost for allogeneic blood products (most conservative scenario). Additionally, we performed a sensitivity analysis with cost data from an industry-initiated analysis with extreme values [15]. Other data in the models were kept unchanged from the original publications, a conservative choice given that the risk of transfusion-related adverse events has decreased, and life expectancy and treatment costs for patients with transfusion transmittable infections (TTI) have improved over the years [16-20]. Introducing more recent data on these parameters would only further decrease the cost effectiveness of EPO.

\section{Results}

\subsection{Results of the Search}

A total of 8436 unique records were screened. Seven records, reporting on five studies, met our eligibility criteria (Fig. 1). These studies are referred to as Basora 2018 [21], Coyle 1999 [13, 22], Coyle 2000 [22, 23], Craig 2006 [14] and SoOsman 2014 [24, 25]. A table detailing the excluded studies and studies awaiting classification can be found in Online Resource 5 (see ESM).

\subsection{Characteristics of Included Studies}

Four of the identified studies are full economic evaluations. Coyle 1999 [13] and Coyle 2000 [23] are cost-effectiveness analyses of preoperative EPO in anaemic patients scheduled for orthopaedic and cardiac surgery, respectively. Coyle 1999 investigated two scenarios: EPO+iron either as a sole intervention or as a means to increase the yield of preoperative autologous blood donation (PAD). The study used 300 units/kg EPO, twice per week for 3 weeks, and $300 \mathrm{mg}$ oral iron three times per day for 3 weeks. Coyle 2000 investigated the effects of preoperative EPO, combined with oral iron as a means to increase the yield of PAD in anaemic elective cardiac surgery patients, who received 300 units/ $\mathrm{kg}$ EPO, twice per week for 3 weeks, and $300 \mathrm{mg}$ oral iron three times per day for 3 weeks [23].

Craig 2006 [14] described a cost-utility analysis within a health technology assessment assessing cost effectiveness of preoperative EPO+iron (600 IU/kg EPO, once per week for 3 weeks and on the day of surgery, with further unspecified iron supplementation) in anaemic orthopaedic surgery patients.

Basora 2018 [21] described a cost-consequence assessment on the impact of preoperative intravenous (IV) ferric carboxymaltose treatment (500-2500 mg, single dose) on transfusion rates in orthopaedic surgery, based on a computer simulation model with 20,000 hypothetical patients, informed by observational data [26]. The majority of patients were assumed to receive tranexamic acid as cointervention in both treatment groups.

So-Osman 2014 [24] described a randomized controlled trial of preoperative EPO+iron (40,000 IU, once per week for 3 weeks and on the day of surgery, and $200 \mathrm{mg}$ oral iron three times/day for 3 weeks), compared with no preoperative EPO+iron, with or without perioperative autologous reinfusion, in orthopaedic surgery, which coupled an economic assessment to its clinical trial results on transfusion rates. For the purpose of this study, data from treatment arms investigating the impact of perioperative autologous reinfusion were not extracted. 


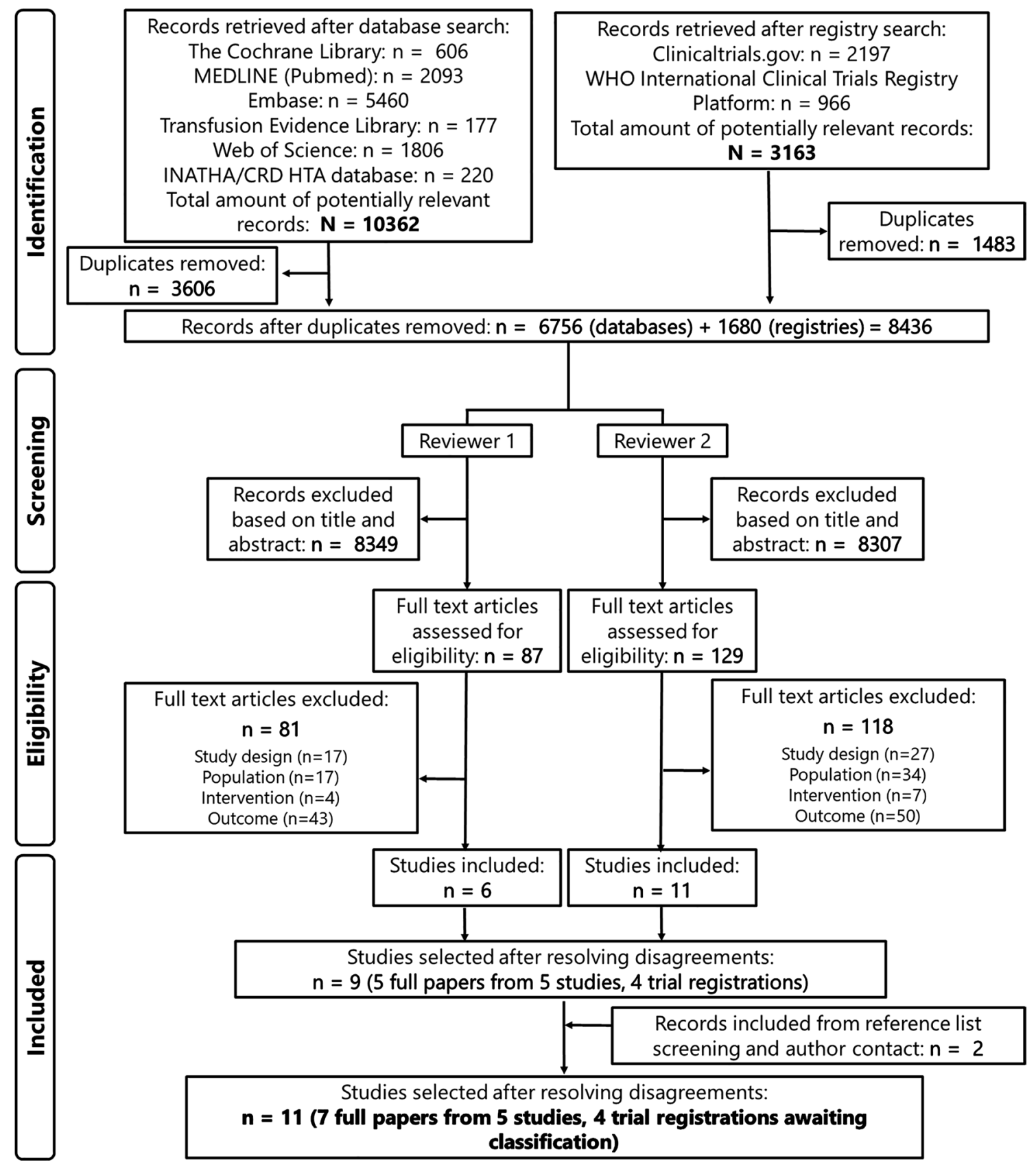

Fig. 1 PRISMA flow diagram of study selection

Costs included in the different studies varied, due to the differences in perspective. Basora 2018 [21] and So-Osman 2014 [24] held a hospital perspective, and therefore only included the direct costs for the hospital during patient hospital stay. The studies by Coyle et al. (1999 and 2000) [13, 23] and Craig et al. [14] all held a broader perspective, taking the views from national health insurance bodies. The studies therefore had a lifetime time horizon, and included costs related to adverse events from transfusion (Table 1).
An overview of treatment effects in the studies is shown in Table 2. A narrative synthesis is given below.

Basora 2018 estimated that preoperative iron significantly reduced the chance of transfusion (relative risk [RR] 0.34, 95\% CI 0.32 to 0.35 ), based on a hypothetical RCT with input from observational data [21].

Three studies investigated the effects of preoperative EPO+iron using RCT evidence [13, 14, 24]. So-Osman 2014 [24] reported a non-significant $31 \%$ decrease in red blood cell $(\mathrm{RBC})$ use (adjusted mean difference [aMD] -0.22 , 
95\% CI -0.5 to 0.05 ), while this decrease was $58 \%$ (MD - 0.73) in Coyle 1999 [13] and even 76\% (MD - 0.493, 95\% $\mathrm{CI}-0.403$ to -0.583 ) in Craig 2006 [14].

There was a statistically significantly reduced chance of transfusion reported in all three studies, ranging from an adjusted odds ratio (aOR) of 0.50 (95\% CI 0.35 to 0.75 ) in So-Osman 2014, over an RR of 0.49 (95\% CI 0.38 to 0.64 ) in Coyle 1999 to an RR of 0.26 (95\% CI 0.2 to 0.35) in Craig 2006.

Two studies investigated the impact of preoperative EPO+iron in addition to PAD in anaemic orthopaedic or cardiac surgery patients $[13,23]$ and reported a reduction in the proportion and mean number of RBC units used per patient (58\% [MD of - 0.09] in cardiac surgery and 26\% [MD of -1 ] in orthopaedic surgery). This corresponds to a statistically significantly decreased chance of transfusion of 0.56 (95\% CI 0.43 to 0.74 ) in cardiac surgery and $0.36(95 \%$ CI 0.15 to 0.88 ) in orthopaedic surgery.

Three studies included the risk of transfusion-related adverse effects and the impact of these events on life expectancy in their analyses [13, 14, 23].

\subsection{Summary of Cost-Effectiveness Findings}

An overview of cost-effectiveness estimates can be found in Table 3, and is described narratively below.

\subsubsection{Incremental Cost per Transfusion or RBC Unit Transfused Avoided}

Incremental cost per transfused patient avoided when using IV iron was estimated to be EUR 831, while the incremental cost per RBC unit transfused avoided was EUR 405 [21]. Cost per transfused patient avoided when using EPO+iron was estimated to be EUR 7300 [24] or GBP 2520 [14]. As co-intervention to $\mathrm{PAD}$, incremental cost per RBC unit avoided of EPO+iron was estimated at CAD 1559 [23].

\subsubsection{Incremental Cost per (Quality-Adjusted) Life-Year Gained}

\section{Base-case analysis}

Incremental cost per life-year (LY) gained for preoperative haemoglobin optimization with EPO+iron in orthopaedic surgery was estimated to be CAD 66.33 million as a sole intervention and CAD 329.28 million as a co-intervention to PAD [13]. As co-intervention to PAD in cardiac surgery, incremental cost per LY gained was CAD 44.6 million [23].

Craig et al. [14] modelled the impact of transfusionrelated illnesses on patient quality of life by expressing cost effectiveness as incremental cost per quality-adjusted LY (QALY). Incremental cost per QALY for EPO+iron in orthopaedic surgery was estimated to be GBP 21.193 million.

Sensitivity analyses conducted in the studies

Both Coyle et al. and Craig et al. conducted extensive sensitivity analyses [13, 14, 23]. Given the unfavourable economic profile, these focussed on scenarios that would improve cost effectiveness of EPO+iron.

EPO+iron in orthopaedic patients was most sensitive to the assumption to only treat heavy bleeders with an extreme efficacy of EPO, higher risks of and costs associated with TTI, a lower quality of life with TTI or lower life expectancies with transfusion (utility of zero) [13]. These sensitivity analyses led to incremental costs per LY gained ranging from CAD 3.47 million to CAD 5.16 million.

When EPO+iron would be used to augment PAD in orthopaedic patients, the estimate was most sensitive to higher risks of and costs associated with TTI, with an estimated incremental cost per LY gained of CAD 4.235 million.

In cardiac surgery patients, where EPO+iron would be used to augment PAD, the estimate was most sensitive to extreme changes in transfusion requirements (transfusion required for all patients not receiving EPO versus none of the patients receiving EPO requiring transfusion), higher risks of and costs associated with TTI and higher chance of transfusion and cost of transfusion, a lower assumed quality of life with TTI or lower life expectancies with transfusion (utility of zero) or a combination of the latter two scenarios [23]. These analyses resulted in incremental cost per LY gained ranging from CAD 102,000 to CAD 4.03 million.

Incremental cost per QALY for EPO+iron was most sensitive to a reduction in the cost of EPO from GBP 79.96 to GBP 2.96, resulting in an incremental cost per QALY of GBP 25,000 or an increase in the cost of allogeneic blood from GBP 235 to GBP 2750 per unit, resulting in an incremental cost per QALY of GBP 28,000 [14].

\subsection{Quality Appraisal}

The quality of reporting of the individual studies was assessed using the Philips checklist and is shown in Online Resource 6 (see ESM). A narrative synthesis per domain of the Philips checklist is given in Table 4 and briefly summarized below.

Basora et al. use limited observational data from their own centre to create a hypothetical RCT, which is used to estimate costs associated with preoperative ferric carboxymaltose as a means to minimize transfusion rates and $\mathrm{RBC}$ use [21]. The model has a very limited scope, from which the costs and consequences are defensible, but the reliability of the data used and the transparency on where data was used or rather assumptions were made is limited. For a broader healthcare insurer or patient perspective, this study provides limited information. 
1128

B. Avau et al.

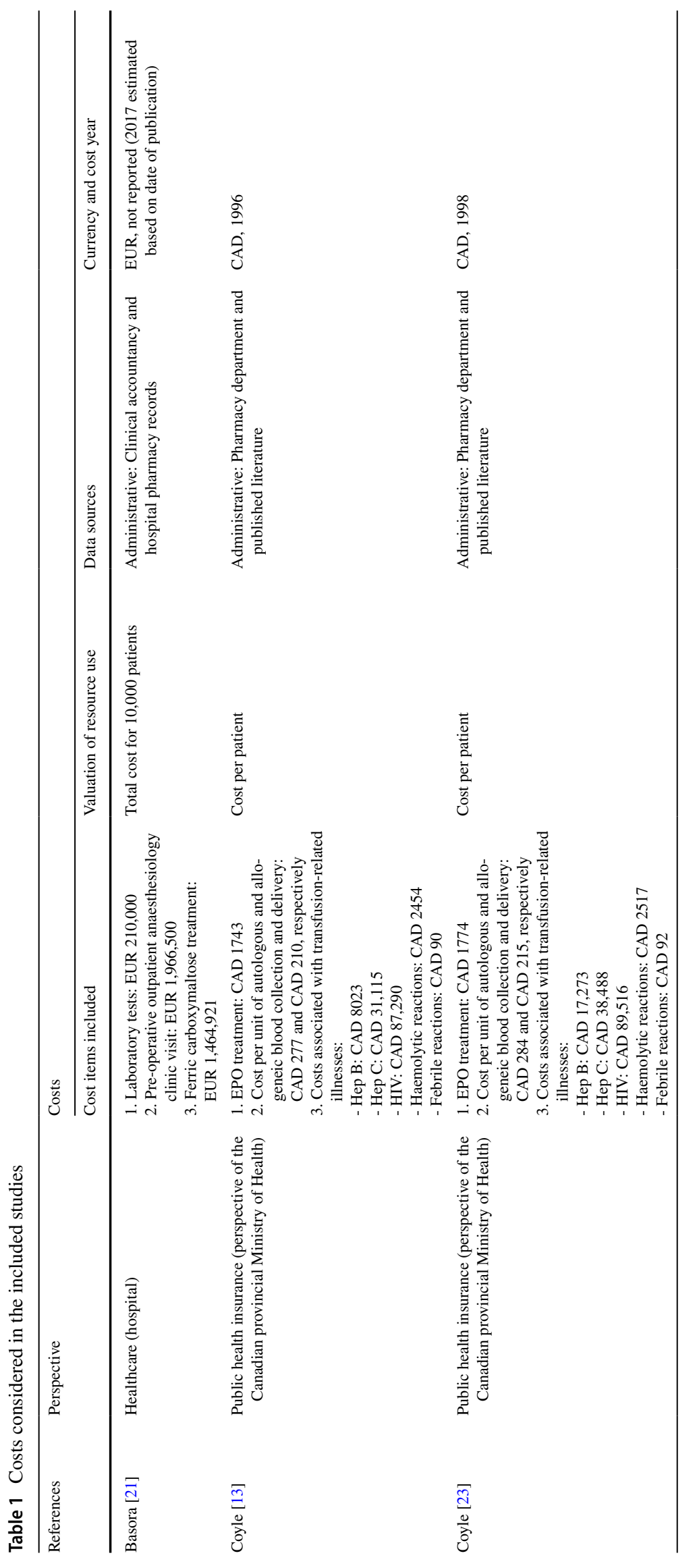

$\triangle$ Adis 


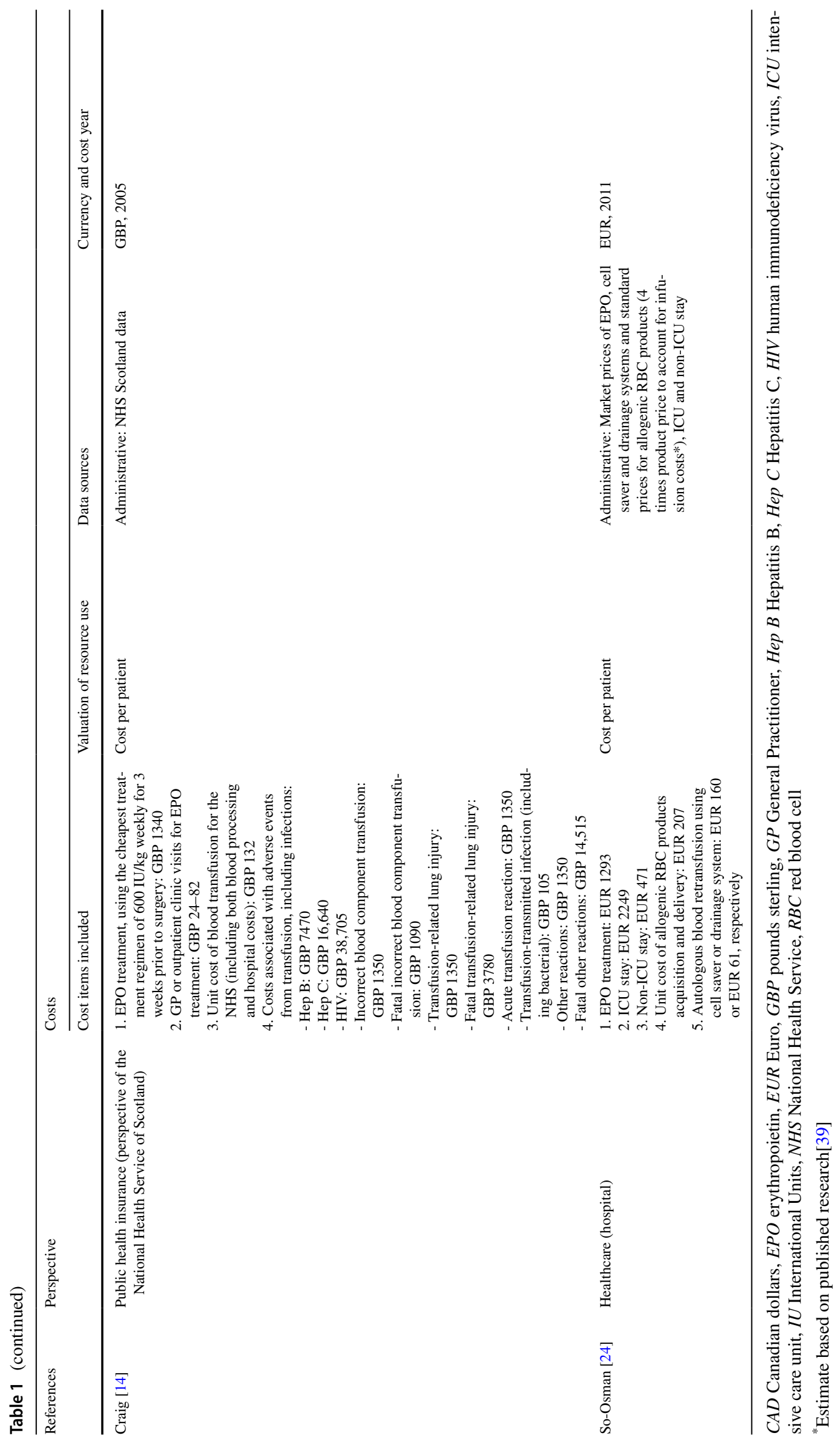


Table 2 Overview of treatment effects described in the economic analysis studies

\begin{tabular}{|c|c|c|c|c|}
\hline References & Outcome & Intervention group & Control group & Effect size \\
\hline \multicolumn{5}{|c|}{ Preoperative IV iron vs no preoperative iron } \\
\hline \multirow{2}{*}{$\begin{array}{l}\text { Basora [21] } \\
\text { Orthopaedic surgery, hypo- } \\
\text { thetical RCT based on } \\
\text { cohort studies }\end{array}$} & $\begin{array}{l}\text { Total number of RBC units } \\
\text { transfused for } 10,000 \\
\text { patients }\end{array}$ & 4341 & 13,336 & $77.5 \%$ decrease \\
\hline & $\begin{array}{l}\text { Proportion of patients trans- } \\
\text { fused }\end{array}$ & $2212 / 10,000(22.1 \%)$ & $6595 / 10,000(65.9 \%)$ & $\begin{array}{l}\text { RR: } 0.34 \\
\text { 95\% CI } 0.32 \text { to } 0.35(43.8 \% \\
\quad \text { decrease) }\end{array}$ \\
\hline \multicolumn{5}{|c|}{ Preoperative $\mathrm{EPO}+$ oral iron vs no preoperative $\mathrm{EPO}+$ oral iron } \\
\hline \multirow[t]{2}{*}{$\begin{array}{l}\text { So-Osman [24] } \\
\text { Orthopaedic surgery, single } \\
\text { RCT }\end{array}$} & $\begin{array}{l}\text { Mean number of RBC units } \\
\text { transfused per patient }\end{array}$ & $0.5 \pm 2.1(n=339)$ & $0.71 \pm 1.6(n=344)$ & $\begin{array}{l}\text { aMD: }-0.22 \\
95 \% \text { CI }-0.5 \text { to } 0.05(30.5 \% \\
\text { decrease })\end{array}$ \\
\hline & $\begin{array}{l}\text { Proportion of patients trans- } \\
\text { fused }\end{array}$ & $54 / 339(16 \%)$ & $89 / 344(26 \%)$ & $\begin{array}{l}\text { aOR: } 0.5 \\
\text { 95\% CI } 0.35 \text { to } 0.75(10 \% \\
\text { decrease })\end{array}$ \\
\hline \multirow{2}{*}{$\begin{array}{l}\text { Coyle [13] } \\
\text { Orthopaedic surgery, system- } \\
\text { atic review of RCTs }\end{array}$} & $\begin{array}{l}\text { Mean number of RBC units } \\
\text { transfused per patient }\end{array}$ & $0.54(n=248)$ & $1.27(n=145)$ & $\begin{array}{l}\text { MD: }-0.73 \\
(57.5 \% \text { decrease })\end{array}$ \\
\hline & $\begin{array}{l}\text { Proportion of patients trans- } \\
\text { fused }\end{array}$ & $80 / 439(18.2 \%)$ & $92 / 245(37.6 \%)$ & $\begin{array}{l}\text { RR: } 0.49 \\
\text { 95\% CI } 0.38 \text { to } 0.64(19.4 \% \\
\text { decrease) }\end{array}$ \\
\hline \multirow{2}{*}{$\begin{array}{l}\text { Craig [14] } \\
\text { Orthopaedic surgery, single } \\
\text { RCT selected from a sys- } \\
\text { tematic review }\end{array}$} & $\begin{array}{l}\text { Mean number of RBC units } \\
\text { transfused per patient }\end{array}$ & $0.15 \pm 0.23(n=458)$ & $0.65 \pm 0.67(n=253)$ & $\begin{array}{l}\text { MD: }-0.49 \\
95 \% \text { CI }-0.40 \text { to }-0.58(76 \% \\
\text { decrease })\end{array}$ \\
\hline & $\begin{array}{l}\text { Proportion of patients trans- } \\
\text { fused }\end{array}$ & $55 / 460(12 \%)$ & $107 / 235(46 \%)$ & $\begin{array}{l}\text { RR: } 0.26 \\
95 \% \text { CI } 0.2 \text { to } 0.35 \\
\text { ( } 34 \% \text { decrease) }\end{array}$ \\
\hline \multicolumn{5}{|c|}{ Preoperative $\mathrm{EPO}+$ oral iron $+\mathrm{PAD}$ vs PAD } \\
\hline \multirow{2}{*}{$\begin{array}{l}\text { Coyle [13] } \\
\text { Orthopaedic surgery, system- } \\
\text { atic review of RCTs }\end{array}$} & $\begin{array}{l}\text { Mean number of RBC units } \\
\text { transfused per patient }\end{array}$ & $0.26(n=267)$ & $0.35(n=173)$ & $\begin{array}{l}\text { MD: }-0.09 \\
(25.7 \% \text { decrease })\end{array}$ \\
\hline & $\begin{array}{l}\text { Proportion of patients trans- } \\
\text { fused }\end{array}$ & $77 / 493(15.5 \%)$ & $88 / 332(26.5 \%)$ & $\begin{array}{l}\text { RR: } 0.56 \\
\text { 95\% CI } 0.43 \text { to } 0.74(11 \% \\
\text { decrease) }\end{array}$ \\
\hline \multirow{2}{*}{$\begin{array}{l}\text { Coyle [23] } \\
\text { Cardiac surgery, systematic } \\
\text { review of RCTs }\end{array}$} & $\begin{array}{l}\text { Mean number of RBC units } \\
\text { transfused per patient }\end{array}$ & $0.74(n=154)$ & $1.74(n=70)$ & $\begin{array}{l}\text { MD: }-1 \\
\text { (58\% decrease) }\end{array}$ \\
\hline & $\begin{array}{l}\text { Proportion of patients trans- } \\
\text { fused }\end{array}$ & $18 / 154(11.6 \%)$ & $25 / 70(35.7 \%)$ & $\begin{array}{l}\text { RR: } 0.36 \\
95 \% \text { CI } 0.15 \text { to } 0.88(24.1 \% \\
\text { decrease) }\end{array}$ \\
\hline
\end{tabular}

95\% CI 95\% confidence interval, (a)MD (adjusted) mean difference, $a O R$ adjusted odds ratio, $E P O$ erythropoietin, $I V$ intravenous, $P A D$ preoperative autologous blood donation, $R B C$ red blood cell, $R C T$ randomized controlled trial, $R R$ relative risk

Coyle 1999 and Coyle 2000 used a rigorous and transparent methodology to assess cost effectiveness of EPO in addition to PAD, or EPO compared with no intervention in an elective orthopaedic or cardiac surgery population [13,23]. The main limitation to these studies seems to be the questionable adaptation of systematically gathered data to the Canadian context, and the datedness of the studies, which cannot take into account new research findings and practical developments in, for example, surgery, transfusion and management of transfusion transmittable disorders.

Craig 2006 is a rigorous and transparent health technology assessment of high quality, assessing cost effectiveness of EPO in an elective orthopaedic surgery population.
Similarly to the studies by Coyle et al., the main limitation is the datedness of the study.

So-Osman et al. related their RCT findings regarding the effectiveness of pre-operative EPO to reduce transfusion rate in elective orthopaedic surgery patients to the costs associated with treatment [24]. The study does not assess the uncertainty of its estimates in any way. For a broader healthcare insurer or patient perspective, this study provides limited information.

\subsection{Sensitivity Analyses}

A source of uncertainty regarding the identified data is that the studies with a lifetime time horizon were conducted over 
Table 3 Overview of cost-effectiveness estimates

\begin{tabular}{|c|c|c|c|}
\hline References & Outcome & Base-case analysis & Range of sensitivity analyses \\
\hline \multicolumn{4}{|c|}{ Ferric carboxymaltose vs standard care in orthopaedic surgery } \\
\hline \multirow[t]{2}{*}{ Basora [21] } & Incremental cost per transfusion avoided & EUR 831 & EUR 606 to EUR 6894 \\
\hline & Incremental cost per allogeneic RBC unit transfused avoided & EUR 405 & EUR 296 to EUR 16,465 \\
\hline \multicolumn{4}{|c|}{$\mathrm{EPO}+$ iron vs standard care in orthopaedic surgery } \\
\hline Craig [13] & Incremental cost per transfusion avoided & GBP 2520 & N/A \\
\hline So-Osman $[2$ & & EUR 7300 & N/A \\
\hline Coyle [13] & Incremental cost per life-year gained & CAD 66.33M & CAD $3.47 \mathrm{M}$ to CAD $54.22 \mathrm{M}$ \\
\hline Craig [14] & Incremental cost per QALY gained & GBP $21.193 \mathrm{M}$ & GBP 25,000 to GBP $21.061 \mathrm{M}$ \\
\hline \multicolumn{4}{|c|}{$\mathrm{EPO}+$ iron + PAD vs PAD in orthopaedic surgery } \\
\hline Coyle [13] & Incremental cost per life year gained & CAD $329.28 \mathrm{M}$ & CAD $4.235 \mathrm{M}$ to CAD $295.95 \mathrm{M}$ \\
\hline \multicolumn{4}{|c|}{$\mathrm{EPO}+$ iron + PAD vs PAD in cardiac surgery } \\
\hline \multirow[t]{2}{*}{ Coyle [23] } & Incremental cost per allogeneic RBC unit transfused avoided & CAD 1559 & N/A \\
\hline & Incremental cost per life-year gained & CAD 44.6M & CAD 102,000 to CAD $473 \mathrm{M}$ \\
\hline
\end{tabular}

$C A D$ Canadian dollars, EPO erythropoietin, EUR Euro, GBP pounds sterling, $M$ million, $P A D$ preoperative autologous blood donation, $Q A L Y$ quality-adjusted life-year, $R B C$ red blood cell

a decade ago $[13,14]$. Therefore, we updated the analyses with more recent data regarding the effects of EPO+iron treatment on utilization of blood products [10] and costs of EPO, iron and blood products (Online Resource 4, see ESM). Coyle 2000 is also an economic evaluation with a lifetime time horizon, but used EPO+iron as a co-intervention to $\mathrm{PAD}$, which is no longer routinely used [23]. Therefore, this model could not be updated with current data. An overview of the adaptations can be found in Table 5. The sensitivity analyses result in estimated costs per (quality-adjusted) LY gained ranging from GBP 3.49 million, or EUR 3.07 million, per QALY gained to CAD 120.14 million, or EUR 77.52 million per LY gained (Online Resource 7, see ESM). These numbers do not differ materially from the original estimates of GBP 21.19 million per QALY gained [14] or CAD 66.33 million per LY gained [13].

\section{Discussion}

The conclusions from the International Consensus Conference on PBM acknowledge the uncertainty regarding cost effectiveness of EPO+iron therapy [9]. Although developed using the GRADE Evidence-to-Decision framework, of which cost effectiveness is an important aspect, cost effectiveness was not considered during formulation of recommendations for clinical practice [27]. To address this shortcoming, a research recommendation was formulated to address the uncertainty regarding cost effectiveness of EPO and iron therapy, which initiated this systematic review.

This systematic review was able to identify only five studies that investigated cost effectiveness of preoperative anaemia treatment in elective surgery patients. Since only one study looked into cost effectiveness of IV iron monotherapy, and this study had a limited time horizon (inhospital only), cost effectiveness of IV iron administration remains unclear due to lack of data [21]. The study reported a cost of EUR 405 per RBC unit transfused or EUR 831 per transfused patient avoided. In addition, several studies on costs associated with preoperative IV iron monotherapy in elective surgery patients did not meet the selection criteria of this review (not reporting an ICER, only a minority of patients treated with iron) [28-30]. These studies conclude that preoperative IV iron could be a dominant intervention (both effective and cost saving). The main reason why these conclusions differ from Basora et al. seems to be the limited scope of Basora et al.'s model, which only considers costs directly related to haemoglobin optimization, and therefore not costs associated with transfusion (cost of blood products and potential impact of transfusion on length of stay). In contrast, the reduction in costs associated with blood transfusion are the main drivers of the cost savings reported by Froessler et al. and Trentino et al. [28-30]. However, given the uncertainty regarding the effectiveness of preoperative IV iron for anaemia correction [10], any conclusion regarding cost effectiveness remains speculative.

Four studies on cost effectiveness of preoperative EPO in combination with oral iron administration were identified $[13,14,23,24]$. Three of these studies were full economic evaluations with a lifetime time horizon [13, 14, 23]. Despite different contexts (North America versus Europe), patient populations (coronary versus orthopaedic surgery patients) and co-interventions (PAD vs none), the overall conclusions of these assessments were similar: routine use of preoperative EPO and oral iron to correct anaemia in elective surgery patients cannot be considered cost effective, with costs per 
Table 4 Summary of the quality and applicability of the included studies, according to the elements of the Philips checklist

\begin{tabular}{ll}
\hline $\begin{array}{l}\text { Refer- } \\
\text { ences }\end{array}$ & Element \\
\hline $\begin{array}{c}\text { Basora } \\
{[21]}\end{array}$ & Structure \\
& - Statement of decision prob- \\
& lem/objective \\
& - Statement of scope/perspec- \\
& tive \\
& - Rationale for structure \\
& - Structural assumptions \\
& - Strategies/comparators \\
& - Model type \\
& - Time horizon \\
& Disease states \\
& - Cycle length \\
& \\
& Data \\
& $\bullet$ Data identification \\
& - Data modelling \\
& $\circ$ Baseline data \\
& $\circ$ Treatment effects \\
& $\circ$ Costs \\
& $\circ$ Quality of life weight (utili- \\
& ties) \\
& - Data incorporation \\
& $\circ$ Assessment of uncertainty \\
& $\circ$ Structural \\
& $\circ$ Heterogeneity \\
& $\circ$ Parameter \\
& Consistency \\
&
\end{tabular}

Assessment

The objective of the model, to investigate cost effectiveness of Hb optimization by using ferric carboxymaltose as a single treatment modality, is clearly defined

The model uses data from relatively small cohorts of patients to perform a computer-simulated RCT of 20,000 hypothetical patients, which limits our confidence in the used treatment estimates The model takes a hospital perspective and limits its time horizon to time in hospital. It focuses on minimization of blood use. Given this, the considered costs and consequences are considered appropriate. However from a healthcare insurer's or patient's point of view, this model is fairly limited, given the potential long-term impact of the intervention on patient outcome and costs associated with this

The rationale for the model's structure, including pre-operative Hb levels, tranexamic acid use and ASA score is appropriate. Considerations are made explicit, but are sometimes (i.e. proportion of patients receiving tranexamic acid, proportion of patients with a certain ASA score, relationship between receiving/not receiving tranexamic acid and transfusion probability) not explained (are these assumed or based on data?)

The methods used for identification of clinical data used in the model are not fully transparent. Where sources of data are described, these originate from small-scale observational research rather than systematic literature reviews of RCTs, which limits our confidence in the treatment effects used in the model

Data sources from the costs used in the model are clearly described. Given the short time horizon, discounting methods are not necessary

The incorporation of data in the model is transparent and appropriate, but structural, methodological uncertainty and heterogeneity are not taken into account

The authors use sensitivity analyses regarding costs associated with outpatient visits and the probability of transfusion to assess the internal consistency of their model. The authors did not use independent data to test the external consistency of their model, but state that their sensitivity analyses regarding blood transfusion probabilities improve the external applicability of their model

Coyle Structure

[13] - Statement of decision problem/objective

- Statement of scope/perspective

- Rationale for structure

- Structural assumptions

- Strategies/comparators

- Model type

- Time horizon

- Disease states

- Cycle length

There is a clear statement of the problem and the objectives of this model. The primary decision maker profiting from this model, provincial drug plan managers, are explicitly stated

The perspective (healthcare insurer) and time horizon (lifetime) are clearly stated and appropriate. As such, incremental cost per life-year gained is a relevantly chosen outcome

The rationale for the structure of the model is explicit and consistent. The sources of data on the effects of the interventions compared on blood transfusion, and proportion of potential adverse effects of blood transfusions are clearly described

Assumptions made are explicitly stated and acceptable

Potential adverse events related to EPO treatment have not been considered in the model, but as these would only further decrease cost effectiveness of EPO, this is acceptable

Data

- Data identification

- Data modelling

- Baseline data

- Treatment effects

- Costs

- Quality of life weight (utilities)

- Data incorporation

- Assessment of uncertainty

- Methodological

- Structural

$\circ$ Heterogeneity

- Parameter

Consistency

- Internal consistency

- External consistency
The data sources for both clinical and cost items used are informed by systematic literature searches and are appropriate, and the generation of baseline data has been described extensively. When multiple papers were available to inform model inputs, the choices made were not always fully transparent. Furthermore, it can be questioned to what extent the adaptation of data retrieved from a systematic review to the Canadian context on solely a chart review of 40 patients from one hospital is reliable

Reduced utilities for patients living with transfusion-related disorders have not been used (i.e. only reduced life expectancy has been taken into account). Sensitivity analyses, however, were performed for extreme values

Extensive scenario analyses have been conducted taking into account extreme scenarios in transfusion costs, incidence adverse transfusion reactions and utilities associated with adverse transfusion reactions. What has not been taken into account in sensitivity analyses are costs associated with EPO treatment and the impact of different transfusion probabilities

The study performed extensive sensitivity analyses, demonstrating that the conclusions made are internally consistent. External consistency has not been formally evaluated, but may be limited for other contexts than the Canadian, given differences in transfusion decisions, life expectancies, treatment costs, baseline chances of transfusion transmitted disorders, etc. 
Table 4 (continued)

\begin{tabular}{|c|c|c|}
\hline $\begin{array}{l}\text { Refer- } \\
\text { ences }\end{array}$ & Element & Assessment \\
\hline \multirow[t]{3}{*}{$\begin{array}{r}\text { Coyle } \\
\text { [23] }\end{array}$} & $\begin{array}{l}\text { Structure } \\
\text { - Statement of decision prob- } \\
\text { lem/objective } \\
\text { - Statement of scope/perspec- } \\
\text { tive } \\
\text { - Rationale for structure } \\
\text { - Structural assumptions } \\
\text { - Strategies/comparators } \\
\text { - Model type } \\
\text { - Time horizon } \\
\text { - Disease states } \\
\text { - Cycle length }\end{array}$ & $\begin{array}{l}\text { There is a clear statement of the problem and the objectives of this model. The primary decision } \\
\text { maker profiting from this model, provincial drug plan managers, is explicitly stated } \\
\text { The perspective (healthcare insurer) and time horizon (lifetime) are clearly stated and appropriate. } \\
\text { As such, incremental cost per life-year gained is a relevantly chosen outcome, more than cost per } \\
\text { allogeneic RBC unit avoided } \\
\text { The rationale for the structure of the model is explicit and consistent. The sources of data on the } \\
\text { effects of the interventions compared on blood transfusion, and proportion of potential adverse } \\
\text { effects of blood transfusions are clearly described } \\
\text { Assumptions made are explicitly stated and acceptable } \\
\text { Potential adverse events related to EPO treatment have not been considered in the model, but as } \\
\text { these would only further decrease cost effectiveness of EPO, this is acceptable }\end{array}$ \\
\hline & $\begin{array}{l}\text { Data } \\
\text { - Data identification } \\
\text { - Data modelling } \\
\circ \text { Baseline data } \\
\text { - Treatment effects } \\
\text { - Costs } \\
\text { - Quality of life weight (utili- } \\
\text { ties) } \\
\text { - Data incorporation } \\
\text { - Assessment of uncertainty } \\
\text { - Methodological } \\
\text { - Structural } \\
\text { - Heterogeneity } \\
\circ \text { Parameter }\end{array}$ & $\begin{array}{l}\text { The data sources for both clinical and cost items used are informed by systematic literature } \\
\text { searches and are appropriate, and the generation of baseline data has been described extensively. } \\
\text { When multiple papers were available to inform model inputs, the choices made were not always } \\
\text { fully transparent. Furthermore, it can be questioned to what extent the adaptation of data } \\
\text { retrieved from a systematic review to the Canadian context on solely a chart review of } 186 \\
\text { patients from one hospital is reliable } \\
\text { Reduced utilities for patients living with transfusion-related disorders have not been used (i.e. } \\
\text { only reduced life expectancy has been taken into account). Sensitivity analyses, however, were } \\
\text { performed for extreme values } \\
\text { Extensive scenario analyses have been conducted taking into account extreme scenarios in transfu- } \\
\text { sion costs, incidence adverse transfusion reactions and utilities associated with adverse transfu- } \\
\text { sion reactions. What has not been taken into account in sensitivity analyses are costs associated } \\
\text { with EPO treatment and the impact of different transfusion probabilities }\end{array}$ \\
\hline & $\begin{array}{l}\text { Consistency } \\
\text { - Internal consistency } \\
\text { - External consistency }\end{array}$ & $\begin{array}{l}\text { The study performed extensive sensitivity analyses, demonstrating that the conclusions made } \\
\text { are internally consistent. External consistency has not been formally evaluated, but may be } \\
\text { limited for other contexts than the Canadian, given differences in transfusion decisions, life } \\
\text { expectancies, treatment costs, baseline chances of transfusion-transmitted disorders, etc. }\end{array}$ \\
\hline \multirow[t]{2}{*}{$\begin{array}{c}\text { Craig } \\
{[14]}\end{array}$} & $\begin{array}{l}\text { Structure } \\
\text { - Statement of decision prob- } \\
\text { lem/objective } \\
\text { - Statement of scope/perspec- } \\
\text { tive } \\
\text { - Rationale for structure } \\
\text { - Structural assumptions } \\
\text { - Strategies/comparators } \\
\text { - Model type } \\
\text { - Time horizon } \\
\text { - Disease states } \\
\text { - Cycle length }\end{array}$ & $\begin{array}{l}\text { The study clearly describes the objective of the model, including the primary decision maker, i.e. } \\
\text { NHS Scotland } \\
\text { The perspective (healthcare insurer) and time horizon (lifetime) are clearly stated and appropriate. } \\
\text { As such, incremental cost per QALY is a relevantly chosen outcome } \\
\text { The structure of the model is appropriate and consistent. Data sources for all of the model's } \\
\text { components are clearly described and based on published scientific literature. Assumptions were } \\
\text { made when no data from literature were available, were explicit, and were tested in sensitivity } \\
\text { analyses }\end{array}$ \\
\hline & $\begin{array}{l}\text { Data } \\
\text { - Data identification } \\
\text { - Data modelling } \\
\text { - Baseline data } \\
\text { - Treatment effects } \\
\text { - Costs } \\
\text { - Quality of life weight (utili- } \\
\text { ties) } \\
\text { - Data incorporation } \\
\text { - Assessment of uncertainty } \\
\text { - Methodological } \\
\text { - Structural } \\
\text { - Heterogeneity } \\
\text { - Parameter }\end{array}$ & $\begin{array}{l}\text { Data for estimating both effect estimates (both benefits and harms) and costs are derived from } \\
\text { rigorous systematic literature searches. These data were then adapted to the Scottish context by } \\
\text { using data on country level, from NHS Scotland. This seems to be appropriate } \\
\text { Utilities were derived from published literature and subject to sensitivity analyses } \\
\text { Uncertainty of the model was assessed using up to seven scenario analyses of extreme adaptations } \\
\text { of the base case, which take into account all potentially important parameters }\end{array}$ \\
\hline
\end{tabular}


Table 4 (continued)

\begin{tabular}{|c|c|c|}
\hline $\begin{array}{l}\text { Refer- } \\
\text { ences }\end{array}$ & Element & Assessment \\
\hline & $\begin{array}{l}\text { Consistency } \\
\text { - Internal consistency } \\
\text { - External consistency }\end{array}$ & $\begin{array}{l}\text { Internal validation was shown by multiple scenario analyses, which were shown to adapt the model } \\
\text { as expected. External consistency has been verified by comparing the study with other existing } \\
\text { cost-effectiveness analyses, which all make the same qualitative conclusions. Nevertheless, the } \\
\text { quantitative estimate may have limited external consistency for other contexts than the } \\
\text { Scottish, given differences in transfusion decisions, life expectancies, treatment costs, baseline } \\
\text { chances of transfusion-transmitted disorders, etc. }\end{array}$ \\
\hline $\begin{array}{l}\text { So- } \\
\text { Osman } \\
{[24]}\end{array}$ & $\begin{array}{l}\text { Structure } \\
\text { - Statement of decision prob- } \\
\text { lem/objective } \\
\text { - Statement of scope/perspec- } \\
\text { tive } \\
\text { - Rationale for structure } \\
\text { - Structural assumptions } \\
\text { - Strategies/comparators } \\
\text { - Model type } \\
\text { - Time horizon } \\
\text { - Disease states } \\
\text { - Cycle length }\end{array}$ & $\begin{array}{l}\text { The objective of the analysis and the primary decision maker targeted are not clearly stated } \\
\text { The perspective (hospital) and time horizon ( } 3 \text { months) of the study are reported, which focuses } \\
\text { on minimization of blood use. The study relates effectiveness outcomes from its own RCT to } \\
\text { treatment costs, and as such does not involve much modelling. From a healthcare insurer's or } \\
\text { patient's point of view, the analysis is fairly limited, given the potential long-term impact of } \\
\text { the intervention on patient outcome and costs associated with this }\end{array}$ \\
\hline & $\begin{array}{l}\text { Data } \\
\text { - Data identification } \\
\text { - Data modelling } \\
\circ \text { Baseline data } \\
\text { - Treatment effects } \\
\text { - Costs } \\
\text { - Quality of life weight (utili- } \\
\text { ties) } \\
\text { - Data incorporation } \\
\text { - Assessment of uncertainty } \\
\text { - Methodological } \\
\text { - Structural } \\
\text { - Heterogeneity } \\
\text { - Parameter }\end{array}$ & $\begin{array}{l}\text { The effectiveness data used in the model originate from the RCT conducted by the authors, and are } \\
\text { accompanied by cost data using standard market prices. Given the short time horizon, discount- } \\
\text { ing methods are not necessary. The data sources are therefore reported in a transparent way; how- } \\
\text { ever, there is very limited information about the rationale for including data in the analysis } \\
\text { The analysis does not take into account any uncertainties or assumptions in the estimates } \\
\text { made, both narratively or via sensitivity analyses }\end{array}$ \\
\hline & $\begin{array}{l}\text { Consistency } \\
\text { - Internal consistency } \\
\text { - External consistency }\end{array}$ & Verification of internal and external consistency was not considered in this analysis \\
\hline
\end{tabular}

$A S A$ American Society of Anesthesiologists, $Q A L Y$ quality-adjusted life-year 


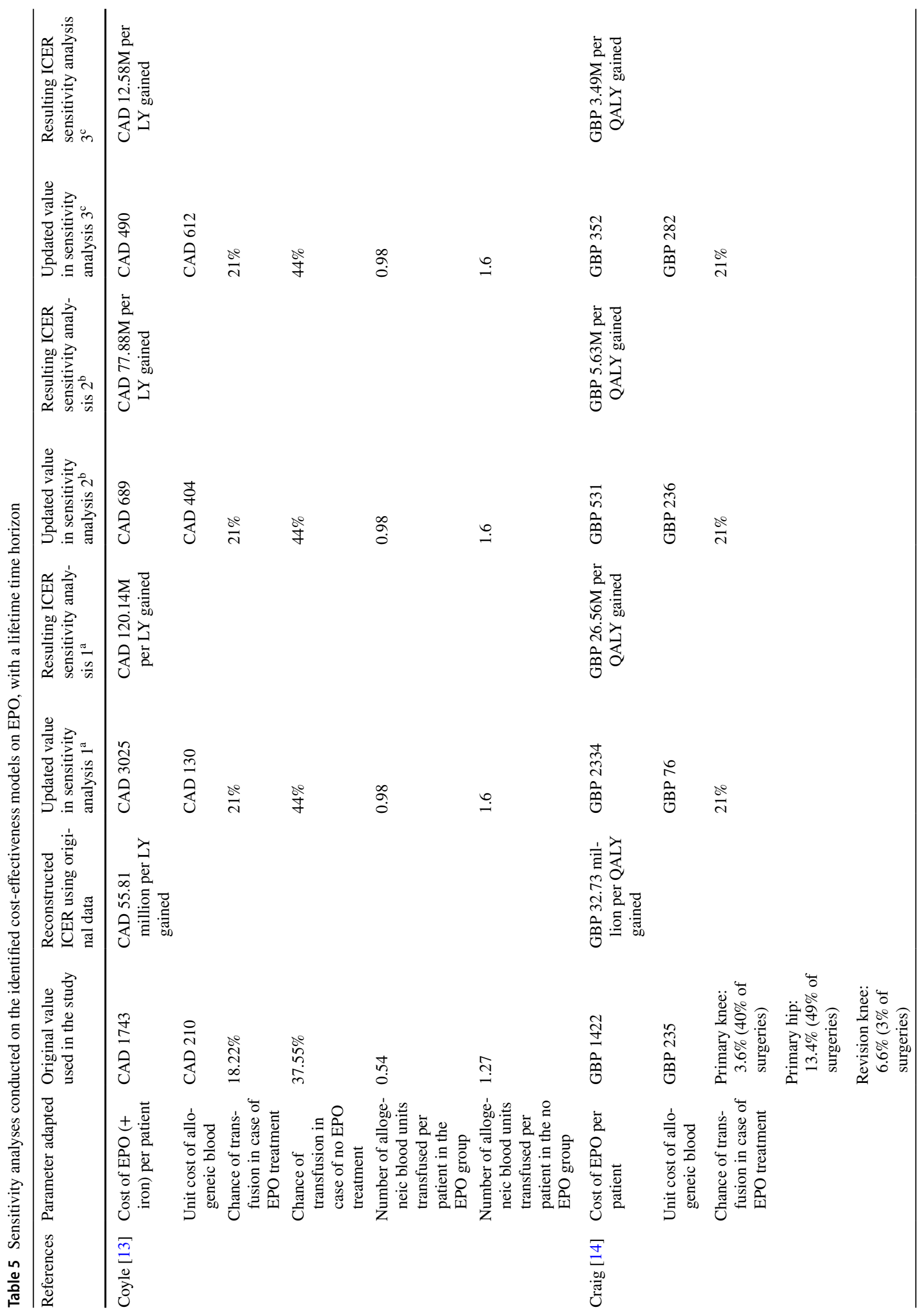




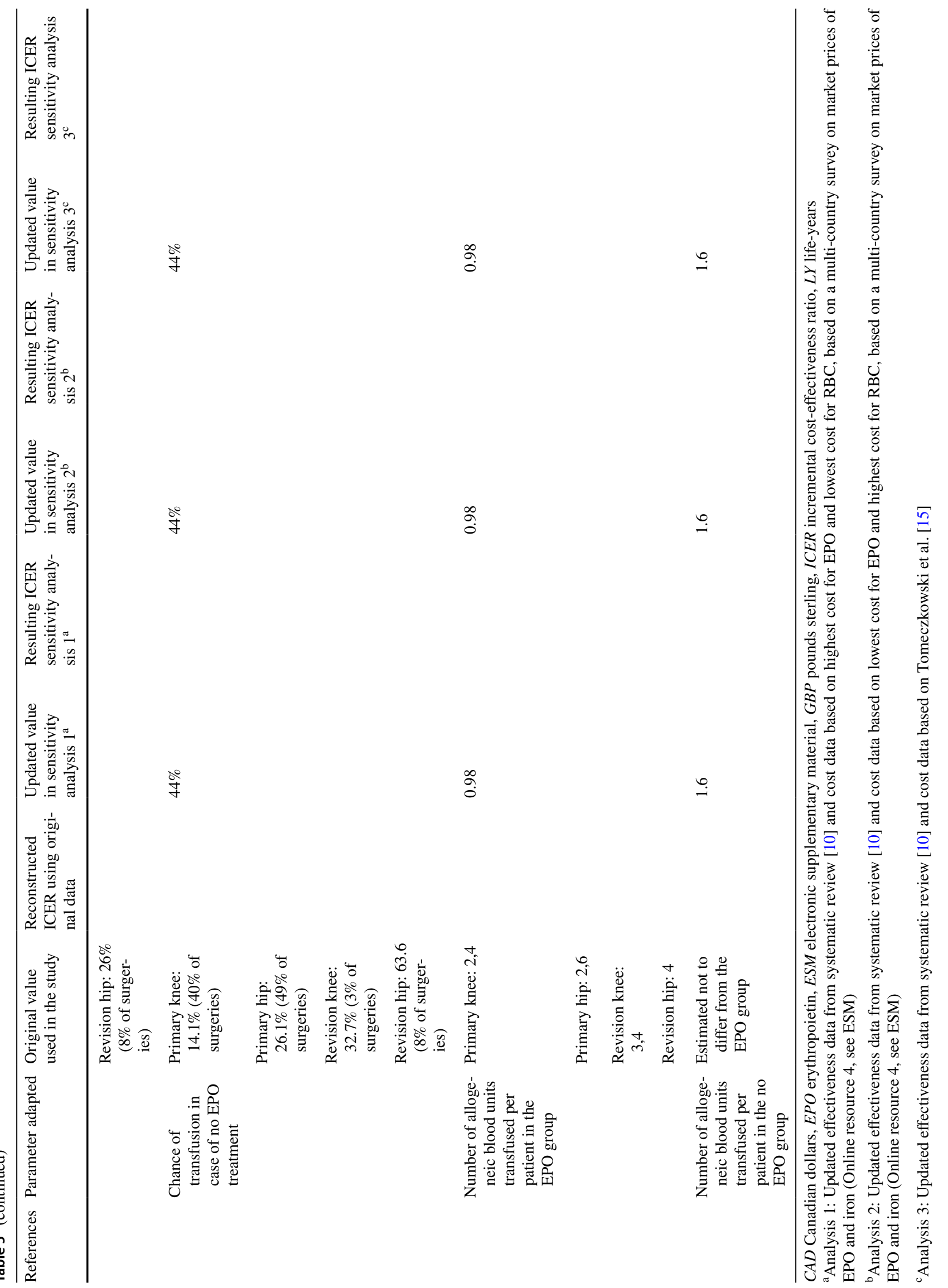


(quality-adjusted) LY gained of several millions in the most realistic scenario according to the study authors. Importantly, these economic evaluations focused on transfusionrelated adverse events, and did not take into account any potential adverse events of EPO nor iron treatment, making these estimates conservative. Extensive sensitivity analyses in the models did not result in differing conclusions, except for the extreme case scenarios of lowering the market price of EPO nearly 400-fold to GBP 2.95 for 10,000 units (current mean market price: GBP 1152, Online Resource 4, see ESM) or raising the market price of blood nearly 25 -fold to GBP 2750 per RBC unit (current mean market price: GBP 118, Online Resource 4, see ESM). These findings illustrate how cost effectiveness is also determined by price setting, based on either 'health economics' (added value, other costs saved for the healthcare system, etc., more typical for the pharmaceutical sector), versus 'at cost' (more typical for non-profit organizations). The fourth study was a randomized controlled trial with an in-hospital time horizon, which made a similar conclusion, based on a cost of EUR 7300 per transfused patient avoided [24].

Several studies on EPO did not meet the eligibility criteria of this systematic review (non-anaemic patient population or not reporting an ICER) [15, 31-33]. However, the overall conclusions from these excluded studies did not differ from the included ones, with the exception of one industryinitiated analysis [15]. Furthermore, additional sensitivity analyses from the current study, using more recent data in the models of Coyle et al. [13] and Craig et al. [14] and also including cost estimates from Tomeczkowski et al. [15], thus updating both cost and effectiveness data with more current estimates, did not lead to a different conclusion.

The fact that several identified studies expressed incremental cost-effectiveness ratio in terms of (quality-adjusted) LYs gained is a strength. In doing so, these studies not only consider a lifetime time horizon, taking into account the long-term effects of an intervention, but also allow objective comparison with other health interventions, useful from a healthcare system's point of view. Although there is some reluctance to define acceptable 'threshold values' for cost effectiveness, the National Institute for Healthcare Excellence in the UK, for example, uses thresholds of GBP 20,000-GBP 30,000 [34], whereas the Irish Health Information and Quality Authority suggests thresholds of EUR 20,000-EUR 45,000 per QALY [35]. The World Health Organisation suggests using three times gross domestic product per person as a country-specific cut-off point for cost-effective healthcare interventions [36]. EPO combined with iron therefore cannot be considered cost effective, even in the wealthiest countries.

This systematic review has several strengths. Firstly, a rigorous methodology has been used to identify, critically appraise and analyse the existing data. In doing so, we can be confident of having a complete overview of the existing body of evidence, which seems to be unambiguous in its conclusions. Secondly, additional sensitivity analyses using recent data from our own up-to-date systematic review on clinical effectiveness of EPO+iron therapy [10], and using recent market prices, further validate the conclusions made in the identified research. Thirdly, this research fills an existing knowledge gap, identified by the ICC-PBM meeting, with conclusions that significantly alter the guidelines and practice, and impact healthcare cost. The findings of this systematic review do not, from a cost-effectiveness point of view, reflect the common clinical practice of preoperative anaemia correction with iron and/or ESAs [37, 38]. Given the beneficial safety profile and relative low cost of blood products [3, 4], any intervention aiming to replace them should be both highly effective and low cost.

Despite its strengths, this research has limitations as well. The identified body of evidence is sparse, especially regarding cost effectiveness of iron therapy, where only one paper on IV therapy was identified. Therefore, any conclusion on cost effectiveness of oral or IV iron therapy remains speculative. Cost effectiveness of EPO together with oral iron therapy was investigated by four studies, which were, however, mostly outdated. Despite the additional sensitivity analyses we conducted, this remains a source of uncertainty. Furthermore, these studies focussed only on orthopaedic or cardiac surgery. The cost effectiveness of EPO in other highrisk surgical procedures (e.g. abdominal surgery) remains unproven [39]. In addition, the evaluations were limited to transfusion avoidance, and adverse events associated with this. Including other clinically important outcomes with a large impact on cost (e.g. return to operating theatre due to bleeding) would have added value. A full health technology assessment with a long-term time horizon on cost effectiveness of pre-operative EPO and/or iron therapy in anaemic elective surgery patients, addressing the current clinical and economical context, is warranted for a more precise ICER estimate.

\section{Conclusions}

Cost-effectiveness of iron monotherapy, whether oral or IV, for anaemia correction in elective surgery patients remains unclear due to lack of data, whereas EPO and oral iron is not found to be cost effective, based on the currently available data originating from only four studies in orthopaedic and cardiac surgery. Future guideline projects should consider these cost-effectiveness data when formulating recommendations on the use of iron and/or ESA therapy to treat patients with preoperative anaemia scheduled for elective surgery. 
Supplementary Information The online version contains supplementary material available at https://doi.org/10.1007/s40273-021-01044-3.

Acknowledgements We are grateful to Dr. Mattias Neyt for providing valuable methodological guidance during the course of this project. Furthermore, we would like to thank Professor Douglas Coyle for providing additional papers and input on his analyses and Ehsan Sadeghian Dehkord for helping with the full-text screening of a Persian paper, and Olga Krasnoukhova for helping with the full-text screening of a Russian paper.

\section{Declarations}

Funding Funding for this project has been provided partly through an Agreement with the European Blood Alliance (EBA) and partly by the Foundation for Scientific Research of the Belgian Red Cross. The contents of this document do not necessarily reflect the views and policies of the EBA, nor does mentioning of trade names or commercial products constitute endorsement or recommendation of use.

Conflict of Interest Relevant financial conflicts of interest directly related to this review: $\mathrm{HV}, \mathrm{JL}, \mathrm{BA}, \mathrm{EDB}, \mathrm{GB}, \mathrm{DF}, \mathrm{JG}, \mathrm{VC}, \mathrm{YO}$ and $\mathrm{PV}$ declared not having any relevant direct financial conflict of interest. PMM received personal fees from Ethos Srl (Advisory Board on PBM) and SUMMEET Srl (Speaker in a meeting on PBM). Relevant financial conflicts of interest not directly related to this review: HV, JL, BA, EDB, VC and PV are employees of Belgian Red Cross-Flanders, which is responsible for supplying adequate quantities of safe blood products to hospitals in Flanders and Brussels on a continuous basis and is funded by the Ministry of Social Affairs. Belgian Red CrossFlanders received a grant from the European Blood Alliance to conduct this review. GB, DF, JG and YO declared not having any other financial conflicts of interest. PMM received personal fees from Editree Srl (creation of training course on porphyria), Eleuthera Srl (AHP Advisory Board), Collage SpA (speaker in a meeting on erythrocytosis), IQVIA (Advisory Board on porphyria), Alnylam (Advisory Board on porphyria). Relevant intellectual conflicts of interest: HV, JL, BA, GB, DF, PMM, YO, EDB, VC and PV declared not having any intellectual conflict of interest. JG declared to be involved in The Danish Health Authority-National Clinical Guideline-Indication for Transfusion with Blood Components-Copenhagen 2018-https://www.sst.dk/da/ udgivelser/2018/nkr-indikation-for-transfusion-med-blodkomponenter

Availability of Data and Material All data generated or analysed during this study are included in this published article and its supplementary information files.

Author Contributions BA: Investigation, formal analysis, writingoriginal draft, visualization. HVR: Conceptualization, investigation, formal analysis, writing - original draft, visualization, supervision, project administration, funding acquisition. JL: Validation, writingreview and editing. GB: Validation, writing - review and editing. DF: Validation, writing - review and editing. PMM: Validation, writingreview and editing. JG: Validation, writing - review and editing. YO: Validation, writing-review and editing. EDB: Conceptualization, writing-review and editing, supervision. VC: Conceptualization, writing-review and editing. PV: Conceptualization, resources, writing-review and editing, supervision.

Ethics approval Not applicable.

Consent to participate Not applicable.

Consent for publication Not applicable.
Code availability Not applicable.

Open Access This article is licensed under a Creative Commons Attribution-NonCommercial 4.0 International License, which permits any non-commercial use, sharing, adaptation, distribution and reproduction in any medium or format, as long as you give appropriate credit to the original author(s) and the source, provide a link to the Creative Commons licence, and indicate if changes were made. The images or other third party material in this article are included in the article's Creative Commons licence, unless indicated otherwise in a credit line to the material. If material is not included in the article's Creative Commons licence and your intended use is not permitted by statutory regulation or exceeds the permitted use, you will need to obtain permission directly from the copyright holder. To view a copy of this licence, visit http://creativecommons.org/licenses/by-nc/4.0/.

\section{References}

1. Carling MS, Jeppsson A, Eriksson BI, Brisby H. Transfusions and blood loss in total hip and knee arthroplasty: a prospective observational study. J Orthop Surg Res. 2015;28(10):48.

2. Rankin D, Zuleta-Alarcon A, Soghomonyan S, Abdel-Rasoul M, Castellon-Larios K, Bergese SD. Massive blood loss in elective spinal and orthopedic surgery: retrospective review of intraoperative transfusion strategy. J Clin Anesth. 2017;37:69-73.

3. Frazier SK, Higgins J, Bugajski A, Jones AR, Brown MR. Adverse reactions to transfusion of blood products and best practices for prevention. Crit Care Nurs Clin North Am. 2017;29(3):271-90.

4. Carson JL, Grossman BJ, Kleinman S, Tinmouth AT, Marques MB, Fung MK, et al. Red blood cell transfusion: a clinical practice guideline from the AABB*. Ann Intern Med. 2012;157(1):49-58.

5. American Association of Blood Banks. Patient Blood Management. 2020. http://www.aabb.org/pbm/Pages/default.aspx. Accessed 10 Nov 2020.

6. Franchini M, Marano G, Veropalumbo E, Masiello F, Pati I, Candura F, et al. Patient Blood Management: a revolutionary approach to transfusion medicine. Blood Transfus. 2019;17(3):191-5.

7. WHO. Haemoglobin concentrations for the diagnosis of anaemia and assessment of severity. 2011. http://www.who.int/vmnis/indic ators/haemoglobin.pdf. Accessed 17 Feb 2020.

8. Thakrar SV, Clevenger B, Mallett S. Patient blood management and perioperative anaemia. BJA Educ. 2017;17(1):28-34.

9. Mueller MM, Van Remoortel H, Meybohm P, Aranko K, Aubron C, Burger R, et al. Patient Blood Management: Recommendations From the 2018 Frankfurt Consensus Conference. JAMA. 2019;321(10):983-97.

10. Van Remoortel H, Laermans J, Avau B, Bekkering G, Georgsen J, Manzini PM, et al. Effectiveness of iron supplementation with or without erythropoiesis-stimulating agents on red blood cell utilization in patients with preoperative anaemia undergoing elective surgery: a systematic review and meta-analysis. Transfus Med Rev. 2021. https://doi.org/10.1016/j.tmrv.2021.03.004.

11. Thomas J, Brunton J, Graziosi S. EPPI-Reviewer 4.0: software for research synthesis. EPPI-Centre Software. London: Social Science Research Unit, Institute of Education, University of London; 2010.

12. Philips Z, Ginnelly L, Sculpher M, Claxton K, Golder S, Riemsma $\mathrm{R}$, et al. Review of guidelines for good practice in decision-analytic modelling in health technology assessment. Health Technol Assess. 2004;8(36):iii-iv, ix-xi, 1-158.

13. Coyle D, Lee KM, Fergusson DA, Laupacis A. Economic analysis of erythropoietin use in orthopaedic surgery. Transfus Med. 1999;9(1):21-30. 
14. Craig J, Brown H, Eastgate J, Macpherson K, Wilson S. The use of epoetin alfa before orthopaedic surgery in patients with mild anaemia. Understanding our advice: the use of epoetin alfa before orthopaedic surgery in patients with mild anaemia. Glasgow: NHS Quality Improvement Scotland (NHS QIS); 2006.

15. Tomeczkowski J, Stern S, Muller A, von H. Potential cost saving of Epoetin alfa in elective hip or knee surgery due to reduction in blood transfusions and their side effects: a discrete-event simulation model. PLoS One. 2013;8(9):e72949.

16. Bolton-Maggs $\mathrm{PH}$, Cohen H. Serious hazards of transfusion (SHOT) haemovigilance and progress is improving transfusion safety. Br J Haematol. 2013;163(3):303-14.

17. Haass KA, Sapiano MRP, Savinkina A, Kuehnert MJ, Basavaraju SV. Transfusion-transmitted infections reported to the national healthcare safety network hemovigilance module. Transfus Med Rev. 2019;33(2):84-91.

18. Sanders GD, Bayoumi AM, Sundaram V, Bilir SP, Neukermans CP, Rydzak CE, et al. Cost-effectiveness of screening for HIV in the era of highly active antiretroviral therapy. N Engl J Med. 2005;352(6):570-85.

19. Juusola JL, Brandeau ML, Long EF, Owens DK, Bendavid E. The cost-effectiveness of symptom-based testing and routine screening for acute HIV infection in men who have sex with men in the USA. AIDS. 2011;25(14):1779-87.

20. Long EF, Brandeau ML, Owens DK. The cost-effectiveness and population outcomes of expanded HIV screening and antiretroviral treatment in the United States. Ann Intern Med. 2010;153(12):778-89.

21. Basora M, Pereira A, Coca M, Tio M, Lozano L. Cost-effectiveness analysis of ferric carboxymaltose in pre-operative haemoglobin optimisation in patients undergoing primary knee arthroplasty. Blood Transfus. 2018;16(5):438-42.

22. Coyle D, Lee KM, Laupacis A, Fergusson DA. Economic Analysis of Erythropoietin Use in Surgery. Ottawa: Clinical Epidemiology Unit, Loeb Research Institute Ottawa Civic Hospital; Departments of Medicine and Epidemiology and Community Medicine, University of Ottawa; 1997.

23. Coyle D, Lee KM, Fergusson DA, Laupacis A. Cost effectiveness of epoetin-alpha to augment preoperative autologous blood donation in elective cardiac surgery. Pharmacoeconomics. 2000;18(2):161-71.

24. So-Osman C, Nelissen RG, Koopman-van GAW, Kluyver E, Pöll RG, et al. Patient blood management in elective total hip- and knee-replacement surgery (Part 1): a randomized controlled trial on erythropoietin and blood salvage as transfusion alternatives using a restrictive transfusion policy in erythropoietin-eligible patients. Anesthesiology. 2014;120(4):839-51.

25. So-Osman C. Cost-effectiveness of patient blood management methods in elective orthopaedic surgery. In: State of the Art Presentations 33rd International Congress of the International Society of Blood Transfusion, in Conjunction with the 33rd Congress of the Ksbt and 2014 Congress of the Korean Hematology Societies, vol 10, no S1. Oxford: Blackwell Science Publ; 2015. pp. 146-9.

26. Basora M, Tio M, Martin N, Lozano L, Salazar F, Sanchez-Etayo $\mathrm{G}$, et al. Should all patients be optimized to the same preoperative hemoglobin level to avoid transfusion in primary knee arthroplasty? Vox Sang. 2014;107(2):148-52.

27. Alonso-Coello P, Schunemann HJ, Moberg J, BrignardelloPetersen R, Akl EA, Davoli M, et al. GRADE Evidence to Decision (EtD) frameworks: a systematic and transparent approach to making well informed healthcare choices. 1: Introduction. BMJ. 2016;353:i2016.

28. Froessler B, Rueger AM, Connolly MP. Assessing the costs and benefits of perioperative iron deficiency anemia management with ferric carboxymaltose in Germany. Risk Manag Healthc Policy. 2018;2018(11):77-82.

29. Trentino KM, Mace H, Symons K, Sanfilippo FM, Leahy MF, Farmer SL, et al. Associations of a preoperative anemia and suboptimal iron stores screening and management clinic in colorectal surgery with hospital cost, reimbursement, and length of stay: a net cost analysis. Anesth Analg. 2020.

30. Trentino KM, Mace HS, Symons K, Sanfilippo FM, Leahy MF, Farmer SL, et al. Screening and treating pre-operative anaemia and suboptimal iron stores in elective colorectal surgery: a cost effectiveness analysis. Anaesthesia. 2020;76(3):357-65.

31. Marchetti M, Barosi G. Cost-effectiveness of epoetin and autologous blood donationin reducing allogeneic blood transfusions incoronary artery bypass graft surgery. Transfusion. 2000;40(6):673-81.

32. Bedair H, Yang J, Dwyer MK, McCarthy JC. preoperative erythropoietin alpha reduces postoperative transfusions in THA and TKA but may not be cost-effective. Clin Orthop Related Res. 2015;473(2):590-6.

33. Moonen AF, Thomassen BJ, Knoors NT, van O, J J, Verburg $\mathrm{AD}$, et al. Pre-operative injections of epoetin-alpha versus postoperative retransfusion of autologous shed blood in total hip and knee replacement: a prospective randomised clinical trial. J Bone Jt Surg Br. 2008;90(8):1079-83.

34. Appleby J, Devlin N, Parkin D. NICE's cost effectiveness threshold. BMJ. 2007;335(7616):358-9.

35. Health Information and Quality Authority. Guidelines for the Economic Evaluation of Health Technologies in Ireland. 2019. https://www.hiqa.ie/sites/default/files/2019-07/HTA-EconomicGuidelines-2019.pdf.

36. Hutubessy R, Chisholm D, Edejer TT. Generalized cost-effectiveness analysis for national-level priority-setting in the health sector. Cost Eff Resour Alloc. 2003;1(1):8.

37. Quarterman C, Shaw M, Hughes S, Wallace V, Agarwal S. Anaemia in cardiac surgery - a retrospective review of a centre's experience with a pre-operative intravenous iron clinic. Anaesthesia. 2020;76(5):629-38.

38. Pinilla-Gracia C, Mateo-Agudo J, Herrera A, Munoz M. On the relevance of preoperative haemoglobin optimisation within a Patient Blood Management programme for elective hip arthroplasty surgery. Blood Transfus. 2020;18(3):182-90.

39. Montroy J, Lavallee LT, Zarychanski R, Fergusson D, Houston $\mathrm{B}$, Cagiannos I, et al. The Top 20 surgical procedures associated with the highest risk for blood transfusion. Br J Surg. 2020;107(13):e642-3. 